\title{
Emergency valve replacement in bacterial endocarditis
}

\author{
HARRYM . WINDSOR AND MARK X. SHANAHAN \\ From St. Vincent's Hospital, Sydney, New South Wales, Australia
}

The object of this report is to record our experience with six patients in whom urgent surgical measures became necessary as a result of cardiac valve destruction following bacterial endocarditis.

The patients constitute a group of six in a total of 200 valve replacements and have been distinguished from three patients in whom, as a result of bacterial endocarditis, valve replacement was undertaken as a routine measure, and 11 patients in a series of 115 mitral valve replacements in whom bacterial endocarditis occurred before surgery.

On one occasion the aortic and mitral valves were involved, on three the aortic valve was involved, and on two the mitral valve was involved.

\section{AORTIC AND MITRAL VALVES}

CASE 1 (R. M. No. 20087) A man aged 32 years developed sudden retrosternal chest pain on 21 January 1966. Examination of the heart at that time revealed no abnormality. On 28 January he developed left-sided abdominal pain accompanied by haematuria. He was admitted to the Pialba Base Hospital, Queensland. Blood cultures grew an alpha haemolytic streptococcus. Murmurs were heard on cardiac examination. About this time he became dyspnoeic, and this rapidly progressed to paroxysmal nocturnal dyspnoea. He was treated with penicillin $1,000,000$ units every four hours.

On 28 February he was transferred to the Chermside Chest Hospital, Brisbane, under the care of Dr. G. Nielsen, where he was found to be in severe heart failure with signs of aortic and mitral incompetence. His temperature became normal on 11 March and thereafter remained so. There was obvious splenomegaly. The haemoglobin was $10.3 \mathrm{~g} . / 100 \mathrm{ml}$. On 22 March he was given a transfusion of $500 \mathrm{ml}$. packed cells.

Despite vigorous treatment he continued to deteriorate, and was flown to the Cardiac Unit, St. Vincent's Hospital, Sydney, late on 25 March. On admission he was found to be gravely distressed, his entire body vibrating with each cardiac pulsation. The blood pressure was $190 / 0 \mathrm{~mm}$. Hg. The jugular venous pressure was raised $8 \mathrm{~cm}$. There was gross hepatomegaly and splenomegaly. He was stuporose with marked Cheyne Stokes respiration. Radiography (Fig. 1) showed marked enlargement of the left ventricle. Cardiac catheterization was done at once. This revealed a brachial artery pressure of $180 / 0 \mathrm{~mm}$. $\mathrm{Hg}$, an aortic root pressure of $80 / 40 \mathrm{~mm}$. $\mathrm{Hg}$, and a left ventricular pressure of $80 / 20 \mathrm{~mm}$. $\mathrm{Hg}$. Cineangiography revealed gross aortic incompetence with moderate mitral incompetence. Deterioration continued, and the patient was taken to the operating room in a near terminal state.

Operation (26 March) Ventricular fibrillation occurred on induction of anaesthesia. It was rectified at once by external massage and electric countershock. Circulation was then maintained until cardiac bypass was established, by cannulation of the left external iliac artery and the right atrium, after vertical sternotomy. As soon as bypass was established the aorta was opened and coronary perfusion was established. The aortic valve had vegetations on all three leaflets. The right leaflet had been almost completely detached and was lying in the cavity of the left ventricle. The left leaflet had numerous friable vegetations on both surfaces. The non-coronary leaflet was distorted and had vegetations on its ventricular aspect. The remains of the valve were excised. When this had been done, two perforations, one above the other, could be seen in the aortic leaflet of the mitral valve. These resulted from the contact of vegetations where the left leaflet of the aortic valve impinged upon the aortic leaflet of the mitral valve. These perforations, which measured $4 \mathrm{~mm}$. and $3 \mathrm{~mm}$. in diameter respectively, were closed with interrupted sutures reinforced with teflon buttresses. When this had been done the aortic valve was replaced with a No. 10 Starr-Edward's prosthesis. In the region of the right aortic leaflet there was no ledge whatsoever. just a smooth surface, and large bites of ventricular myocardium were obtained with the sutures.'The postoperative course was uneventful. He was discharged on 9 April and has remained well. Culture of the vegetations from within the left ventricle was sterile.

\section{AORTIC VALVE}

CASE 2 (C. M. No. 18506) A man aged 44 years was admitted to St. Vincent's Hospital on 27 December 1965. He complained of dizziness and recurrent nose bleeding. His temperature was $37.6^{\circ} \mathrm{C}$. and rose to 


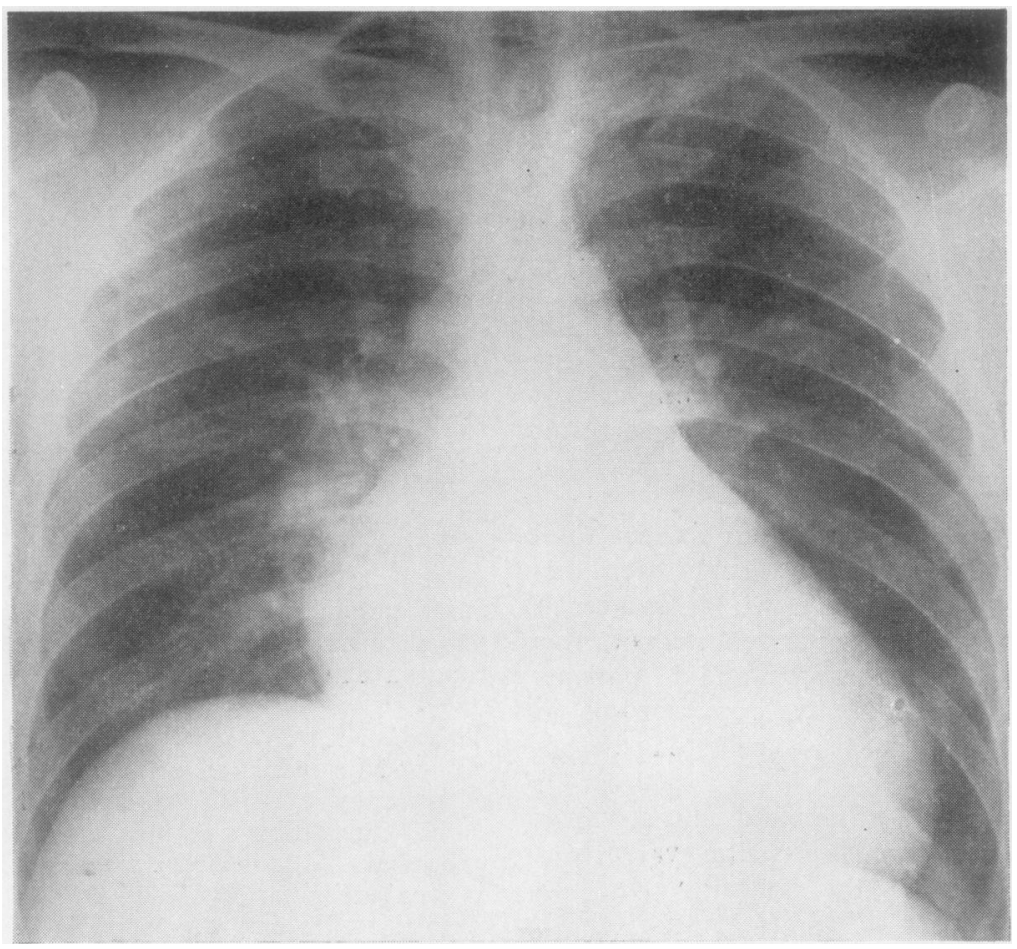

FIG. 1. Case 1.

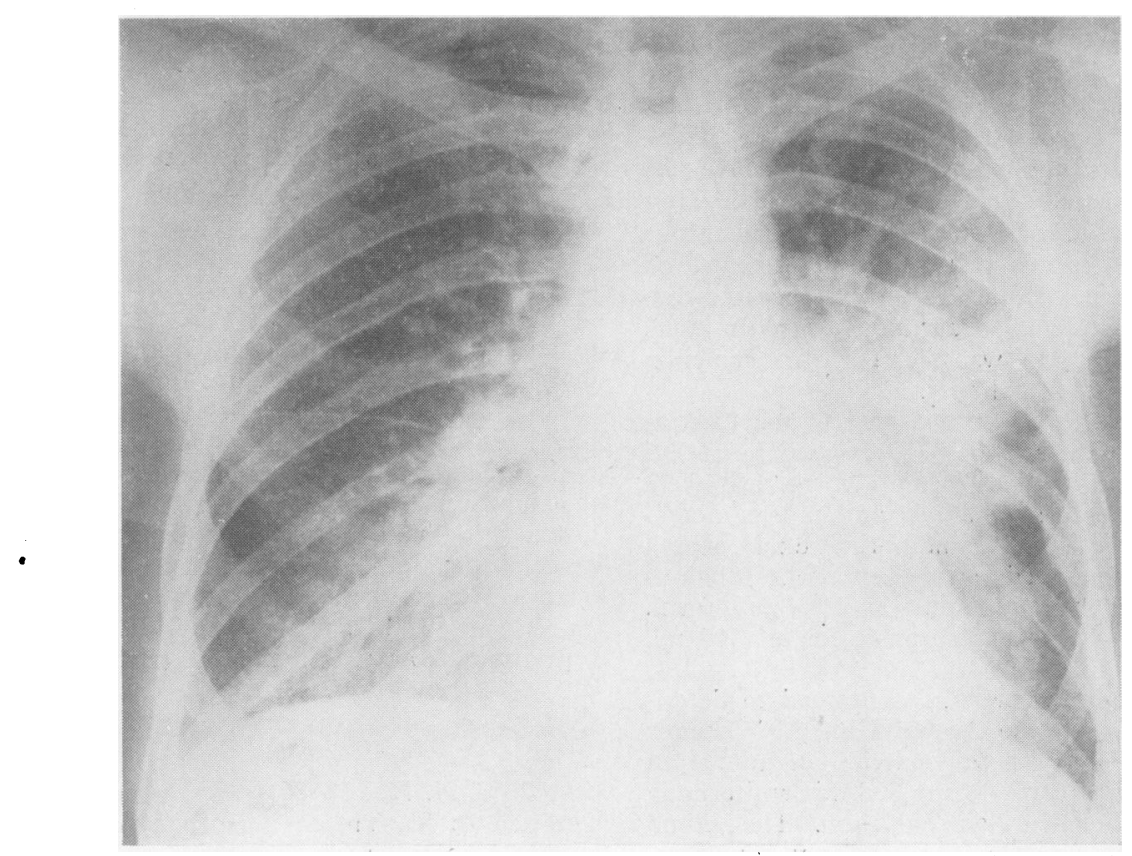

FIG. 2. Case 2. 
$39.2^{\circ} \mathrm{C}$. at night. The pulse rate was 120 and the blood pressure $100 / 70 \mathrm{~mm}$. Hg. There was a faint apical systolic murmur. The liver was enlarged $5 \mathrm{~cm}$. There was no splenomegaly. The haemoglobin was $7 \mathrm{~g} . / 100 \mathrm{ml}$. Blood cultures all grew Neisseria perflava. The same organism was grown from a tonsil swab. On 5 January 1966 an aortic diastolic murmur was noted and signs of aortic incompetence soon became apparent.

Antibiotics were begun on 5 January. The infection proved most resistant, and, despite adequate dosage with successively penicillin, streptomycin, erythromycin, and cephalosporin, the headache, anorexia, and raised temperature continued. The temperature finally became normal on 3 April, and thereafter remained so. The medical aspects are to be reported elsewhere (Breslin et al., 1967).

Throughout this period the haemodynamic state worsened. The blood pressure was $120 / 40 \mathrm{~mm}$. Hg. There was a well-marked gallop rhythm. Pulmonary oedema supervened. Vigorous measures failed to improve the situation. The heart continued to enlarge. The chest radiograph (Fig. 2) showed pulmonary oedema.

Cardiac catheterization and cineangiography revealed gross aortic incompetence with slight mitral incompetence.

Operation (18 April) There were numerous vegetations on all three aortic leaflets. There were two perforations in the right leaflet, one measuring $4 \mathrm{~mm}$. in diameter and the other $2 \mathrm{~mm}$. A large perforation in the non-coronary leaflet measured nearly $1 \mathrm{~cm}$. in diameter. These two leaflets were, for practical purposes, destroyed. The left leaflet was normal except for attached dependent vegetations. All three leaflets were excised and replaced with a No. 9 StarrEdward's prosthesis. The aortic leaflet of the mitral valve was inspected and proved to be normal.

Post-operative recovery was uneventful. The patient was discharged on 10 May 1966 and has remained well since. Culture of the vegetations was sterile.

CASE 3 (E. L.) A 34-year-old mother of two was on holiday on the Queensland Gold Coast when on 1 September 1965 she developed a febrile illness characterized by rigors, listlessness, and tachycardia. She was seen by a doctor, who made a diagnosis of bacterial endocarditis on the basis of fever, tachycardia, and a basal cardiac murmur. She denied knowledge of a previous heart murmur. Blood cultures grew Streptococcus pneumoniae. Parenteral penicillin was begun. Her condition slowly deteriorated, and on 15 September she was transferred to the Chermside Chest Hospital in Brisbane.

On admission she was comatose. She had a left facial palsy, bilateral extensor responses, and a stiff neck. Blood cultures taken that day were sterile. The cerebrospinal fluid was turbid and contained many polymorphonuclear leucocytes and a small number of Gram-positive cocci. Culture was sterile. Auscultation of the heart suggested aortic incompetence. The brachial blood pressure was $80 / 35 \mathrm{~mm}$. Hg. The haemoglobin was $12.3 \mathrm{~g} . / 100 \mathrm{ml}$. and the white cell count 11,300. A chest radiograph showed a heart of normal size. The E.C.G. showed first-degree heart block.

Therapy consisted of 16 million units of penicillin intravenously and $1 \mathrm{~g}$. streptomycin daily. The penicillin was gradually reduced to 1 million units every six hours.

Improvement was dramatic. She soon became conscious, and at the end of a week all neurological signs had disappeared. During this period the cardiac sounds changed appreciably, and on 24 September the predominant bruit was a harsh machinery murmur maximal at the sternal edge in the fourth left intercostal space.

It was not until 7 October that right heart failure became evident. This became severe. The heart enlarged rapidly and pulmonary plethora appeared. The electrocardiogram showed complete atrioventricular dissociation. The cardiac signs were those of gross aortic incompetence and a probable sinus of Valsalva fistula.

On 12 October she became oliguric and confused, and by 14 October was anuric and comatose. Peritoneal dialysis on 13 October resulted in the removal of $5,900 \mathrm{ml}$.

She was seen by one of us (H. W.) for the first time on 14 October. It was felt that only urgent surgical intervention offered her a chance of survival. This was proceeded with despite the absence of catheter studies.

Operation (14 October) Cardiac pulmonary bypass was established by cannulation of the left external iliac artery and both venae cavae through the right atrial appendage, after vertical division of the sternum and pericardium. A marked thrill was felt over the right atrium, and it was obvious that there was a regurgitant jet into the atrium just above the tricuspid valve. Before the institution of bypass the heart went into complete heart block with a rate of 30 and a marked fall in blood pressure. Following the institution of bypass the patient was cooled, and at a temperature of $30^{\circ}$ C. the aorta was cross-clamped and the right atrium opened. There was a fistula present just above the tricuspid valve measuring $8 \mathrm{~mm}$. in diameter. It was closed with interrupted sutures reinforced with teflon buttresses. The aortic cross-clamp was then released. The left ventricle filled with blood, and it was quite obvious that there was severe incompetence of the aortic valve. The aorta was again cross-clamped and then opened with an oblique incision just above the valve. The non-coronary leaflet had literally been swept away. Its place was taken by numerous vegetations dependent in the cavity of the left ventricle. All evidence of its previous attachment had disappeared. The other two leaflets were relatively normal.

Perfusion of both coronary arteries was started and the aortic valve was excised and replaced with a No. 8 
Starr-Edward's prosthesis. In the region of the noncoronary leaflet the stitches were passed through the aortic wall and tied outside over teflon. Defibrillation was easily accomplished, but the heart would beat only when stimulated by finger tap. For this reason a pacemaker lead was placed in the right ventricle. This satisfactorily activated the heart and maintained a reasonable blood pressure. The patient tolerated the procedure quite well and was in a satisfactory condition with a systolic pressure of $80 \mathrm{~mm}$. $\mathrm{Hg}$ at the termination of the operation.

Post-operative Course Over a period of two days she became conscious and was able to breathe without respirator assistance. Kidney function returned, and pacing was necessary only intermittently. Cardiac rhythm varied between complete heart block, with occasional ventricular capture, to sinus rhythm. The blood pressure was $120 / 60 \mathrm{~mm}$. $\mathrm{Hg}$ and the haemodynamics were quite satisfactory. This improvement continued for seven days. Culture of the vegetations removed from the left ventricle was sterile.

The serum bilirubin, which on the second postoperative day was $6 \mathrm{mg} . / 100 \mathrm{ml}$., rose to $26 \mathrm{mg}$./ $100 \mathrm{ml}$. This was associated with a raised serum alkaline phosphatase of 60 to $80 \mathrm{~K}$.-A. units. Flocculation tests were normal. Both urine and faeces contained bile. The urine and serum amylase were normal.

On 22 October she again deteriorated, becoming oliguric and semicomatose despite a good circulation. Candida albicans was grown from the urine and faeces. Penicillin was suspended and nystatin was begun. The deterioration continued. On 25 October peritoneal dialysis was reinstituted, steroids were commenced, and loading doses of kanamycin and colimycin were given. The haemoglobin, which had been stable at $13 \mathrm{~g} . / 100 \mathrm{ml}$., was now $8.1 \mathrm{~g} . / 100 \mathrm{ml}$. A transfusion of $1,000 \mathrm{ml}$. of whole blood was given over 18 hours. At this time the Schumms' test, the Coombs' test, and the urine urobilinogen were all negative. Death occurred on 27 October.

Necropsy All the internal organs, in particular the liver, spleen, and kidneys, had areas of small yellowish nodules which on smear and culture grew Candida albicans. The spleen contained numerous cavities with thick yellowish walls. There were numerous small areas of old softening throughout both cerebral hemispheres. The pleura and pericardium contained Candida. The fistula closure was intact, as was the aortic prosthesis. There were no vegetations on the prosthesis.

CASE 4 (C.P. No. 21066) A 25-year-old soldier was transferred to this unit from Singapore with a diagnosis of bacterial endocarditis and aortic incompetence. Six weeks previously, whilst on jungle patrol in Borneo, he began a period of vague ill health with malaise, fever, and headache. Exertional dysponea, orthopnoea, cough, and sputum developed, and he was treated in Sarawak for bronchopneumonia. Twelve days before admission to this unit he became acutely more dyspnoeic, pale, and cyanosed. Blood pressure was noted to be $130 / 0 \mathrm{~mm}$. Hg. Tachycardia, gallop rhythm, and a to-and-fro murmur at the left sternal edge were present. The patient was transferred to Singapore, where blood cultures were taken but were negative. Repeated chest radiographs showed progressive pulmonary oedema. He was given massive doses of penicillin and streptomycin, but continued to deteriorate.

On admission to this unit on 19 May 1966 he had the signs of gross aortic incompetence and pulmonary oedema (Fig. 3). He was dyspnoeic at rest and had to remain sitting up. None of the usual signs of bacterial endocarditis was present. Cardiac catheterization and cineangiocardiography were performed and showed moderate pulmonary hypertension, gross aortic incompetence, and an aneurysm of the left sinus of Valsalva. The brachial artery pressure was $130 / 0 \mathrm{~mm}$. Hg. The central aortic pressure 90/34 $\mathrm{mm}$. $\mathrm{Hg}$ and the left ventricular pressure $90 / 30 \mathrm{~mm}$. Hg. Haemoglobin was 12 g. $/ 100 \mathrm{ml}$., white cell count 18,200 , and the sedimentation rate $90 \mathrm{~mm}$. per hour (Westergren). The serum electrolytes, $p \mathrm{H}$, buffer base, and $\mathrm{PCO}_{2}$ were normal. Arterial oxygen saturation was $86 \%$ breathing intranasal oxygen.

His condition was not desperate, and it was decided to wait until morning, 12 hours later, before carrying out valve replacement. His condition remained stable until premedication was given one hour pre-operatively, when he at once became deeply cyanosed, stuporose, restless, and uncooperative. On transfer to the operating table before induction of anaesthesia, he began to struggle violently. Complete heart block occurred, and this was followed by cardiac asystole. External cardiac massage and tracheal intubation were performed at once and within moments cardiac action began again and a pulsation could be felt in the major vessels. However. the mean arterial pressure, by direct measurement in the left brachial artery, was only $30 \mathrm{~mm}$. Hg.

A vertical sternotomy was rapidly performed to establish cardiopulmonary bypass. The patient was ready for bypass in two and a half minutes, but before the pump oxygenator could be brought into the room, fully primed and with connexions complete, ventricular fibrillation occurred. This could not be reversed, neither could a systolic pressure be produced by open massage. The procedure was terminated.

Necropsy There was a large mass of calcium with superimposed vegetations on the ventricular aspect $\stackrel{\mathscr{D}}{+}$ of the left and right leaflets. The left leaflet was 0 perforated, and this extended through the commissure into the base of the right leaflet, resulting in a large regurgitant orifice. There was an aneurysm of the

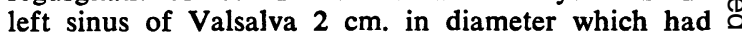
eroded the pulmonary artery almost to the point of perforation. Culture of the vegetations was sterile. 


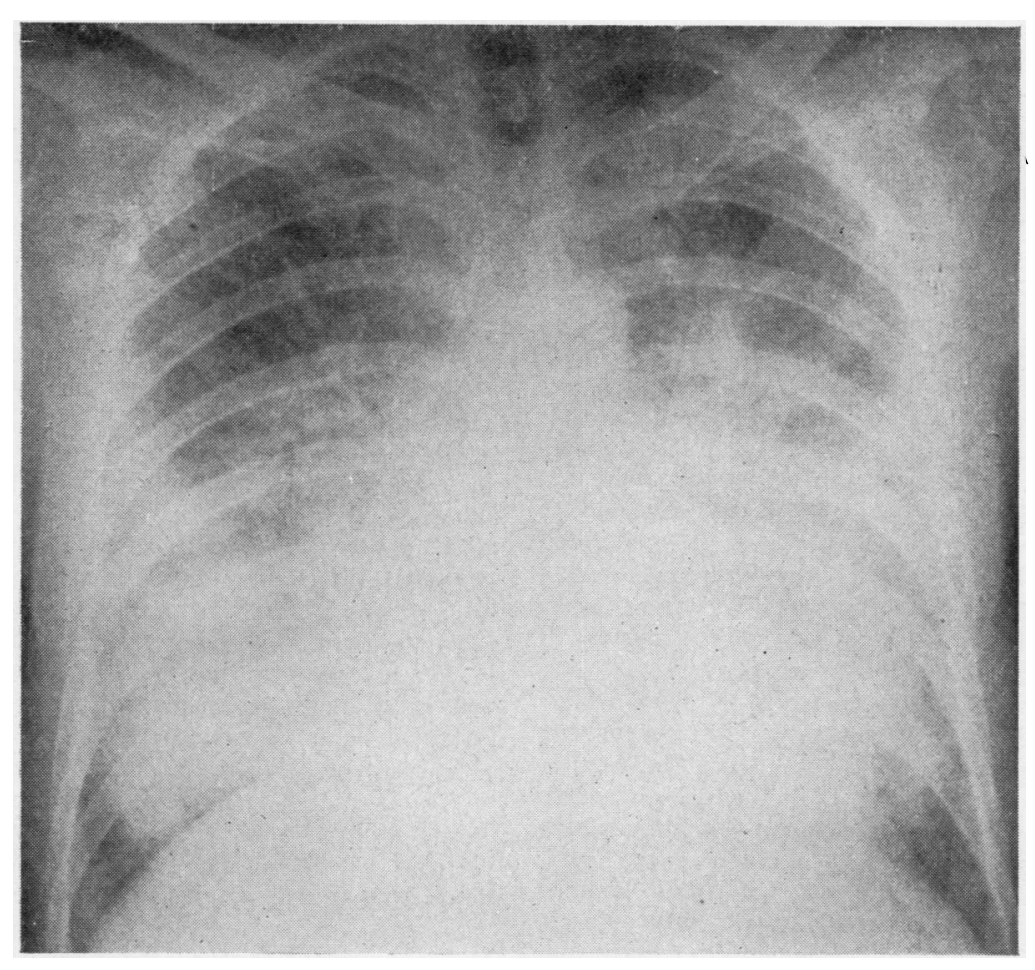

FIG. 3. Case 4.

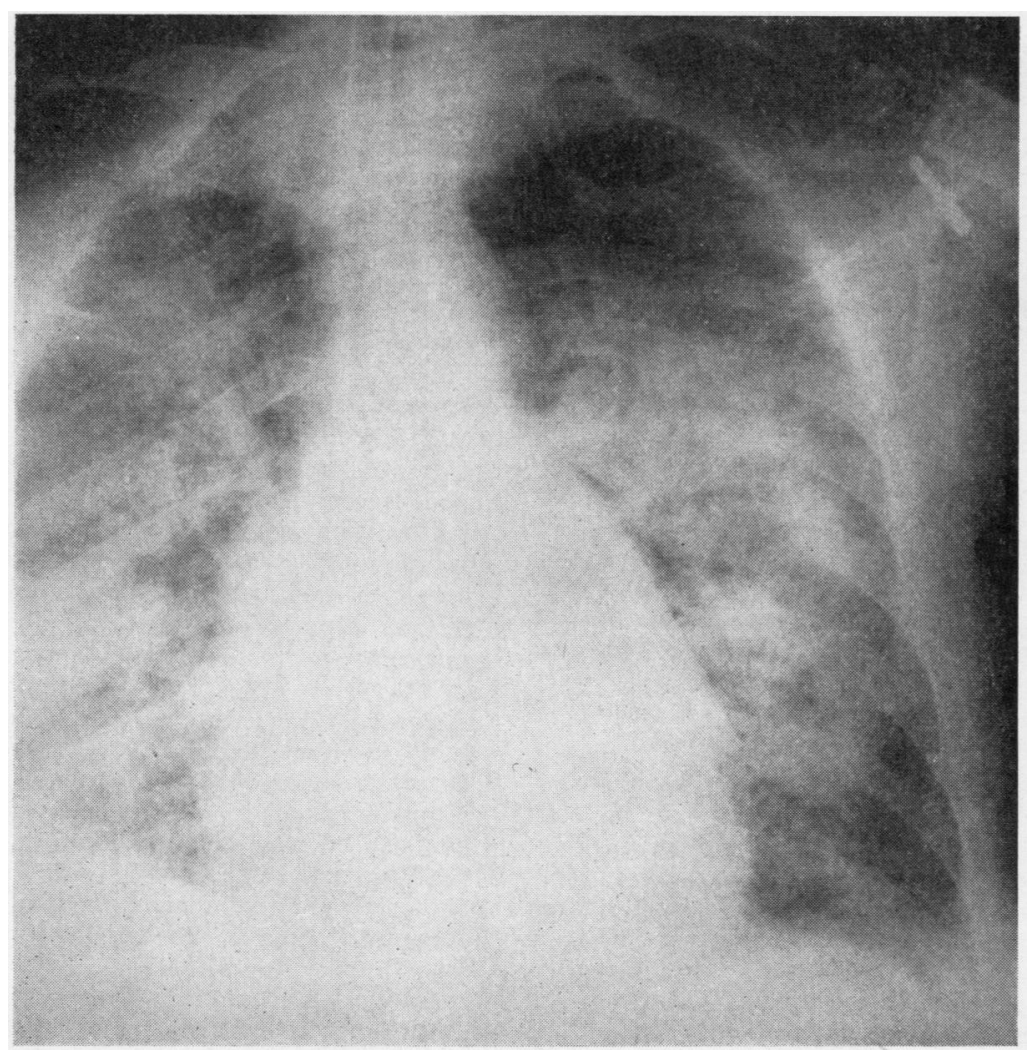

FIG. 4. Case 5. 
MITRAL VALVE

CASE 5 (R. M. No. 19958) A man aged 58 had a tooth extracted in December 1965. Following this he became tired and listless. During January 1966 he became increasingly breathless and developed ankle oedema. He was known to have had a heart murmur. On 3 March 1966, following a dizzy turn, he developed a right facial paresis. On 13 March he was awakened by an attack of acute pulmonary oedema. Soon after he became aphasic. He was admitted to the Coledale Hospital, N.S.W., where he was noted to have a right hemiparesis. This improved during the next three days. Reddish painful spots were present on the fingers and palms of the hands. A loud apical systolic murmur was noted.

On 19 March he was admitted to St. Vincent's Hospital. At that time the pulse rate was 100 per minute and the blood pressure $110 / 55 \mathrm{~mm}$. $\mathrm{Hg}$. The jugular venous pressure was normal. There was slight ankle oedema. There was a moderate pansystolic murmur heard all over the precordium, maximal at the apex. $\mathrm{He}$ had signs of a right hemiparesis. The haemoglobin was $7.8 \mathrm{~g} . / 100 \mathrm{ml}$. Seven blood cultures grew Staphylococcus albus, coagulase negative, sensitive to penicillin. Massive doses of penicillin and streptomycin were begun on $25 \mathrm{March}$, and subsequently methicillin $6 \mathrm{~g}$./day was added. He was given a transfusion of $500 \mathrm{ml}$. packed cells.

Until this time the cardiac state gave little concern ; however, on 25 March atrial fibrillation began and soon became rapid and uncontrollable. Pulmonary oedema supervened. A radiograph of the chest (Fig. 4) showed marked pulmonary oedema. On $30 \mathrm{March}$ the blood pressure was $90 / 20 \mathrm{~mm}$. Hg. On $31 \mathrm{March}$ the pulse rate was 160 , there were crepitations over both lung fields, and the chest radiograph had deteriorated further. On 1 April the blood pressure was $60 / 20 \mathrm{~mm}$. Hg. There were pistol shots on auscultation of the femoral vessels, and for this reason cardiac catheterization and cineangiography were performed. They revealed gross mitral incompetence but no aortic lesion. A decision was made to carry out emergency surgery. On arrival in the operating room the blood pressure was $55 / 0 \mathrm{~mm}$. Hg. Temperature was $35 \cdot 2^{\circ} \mathrm{C}$. All extremities were quite cold and deeply cyanosed. He subsequently developed a patch of gangrene on the left big toe. He was stuporose, in pulmonary oedema, and being sustained by assisted respiration through an endotracheal tube.

Operation (1 April, 5 p.m.) Cardiopulmonary bypass was established by cannulation of the left external iliac artery and the outflow tract of the right ventricle, through a left postero-lateral thoracotomy. The pericardium was not opened until the patient had been heparinized and the iliac artery cannulated. It was then opened and bypass was established at once. Ventricular fibrillation supervened during the establishment of bypass. The aortic leaflet of the mitral valve was flail. Most of the chordal attach- $\frac{\overrightarrow{\bar{F}}}{+}$ ments had ruptured. The ruptured ends of the chordae were covered with vegetations. There were vegeta- $\frac{\bar{O}}{\bar{D}}$ tions on the papillary muscles and on the endocardium $\frac{\bar{c}}{\rightarrow}$ of the left ventricle. The mural leaflet was intact but $\mathbb{\AA}$ thickened and slightly calcified. There were vegetations on its free margin. It had obviously been a s rheumatic valve. The valve, together with all chordal $\vec{O}$ remnants, papillary muscles, and vegetations, was $\vec{\longrightarrow}$ excised and replaced with a No. 4 Starr-Edward's $\vec{\omega}$ prosthesis. At the end of the operation the heart was in sinus rhythm at a rate of 100 , and the blood $x$ pressure was $120 / 80 \mathrm{~mm}$. $\mathrm{Hg}$. Despite the $200 \mathrm{mEq}$ N of bicarbonate given towards the end of bypass, the $p \mathrm{H}$ was $7.01, \mathrm{PCO}_{2} 60 \mathrm{~mm}$. $\mathrm{Hg}$, and buffer base 29.5 i mEq. A further $200 \mathrm{mEq}$ of bicarbonate was given. O At 2 a.m. the $p \mathrm{H}$ was $7 \cdot 24$ and $\mathrm{PCO}_{2} 49$. A further $160 \mathrm{mEq}$ of bicarbonate was given, after which the $\vec{c}$ $p \mathrm{H}$ was $\mathbf{7 \cdot 4}$. The haemodynamic state was quite satisfactory and thereafter gave no concern.

Post-operative Course It was apparent from the completion of the operation that the prognosis would $\vec{\varphi}$ depend on the cerebral state. He was slow to wake. thereafter was difficult to rouse, and within 24 hours io began to have right-sided fits. During the following week the chest radiographs returned to normal. Haemodynamics and renal function were normal, as $\overline{0}$ were the serum electrolytes and blood elements. The $\frac{2}{8}$ fits became more frequent, the depth of unconscious- $\unrhd$ ness suddenly deepened on 7 April, and he died on $\overrightarrow{\vec{O}}$ 8 April.

The haemodynamic state had been rectified, but the addition of bypass to severe prolonged hypotension, acidosis, and pulmonary oedema proved too much for the pre-existing cerebral damage.

Necropsy A large area of cerebral softening was found. There were no vegetations on the prosthesis.

There was no evidence of infection in the other organs.

CASE 6 (R. M. No. 859) A man aged 42 years devel- 옥 oped rigors, fever, splenomegaly, and jaundice 16 D months after mitral valve replacement. Nine consecu- 은 tive blood cultures grew Staphylococcus albus. $\mathrm{Re}-$ sponse to treatment with methicillin was excellent. o $\mathrm{He}$ was discharged six weeks after admission with $N$ apparently normal haemodynamics. Six weeks later $N$ on 24 March 1965 he was admitted in pulmonary $\omega$ oedema and congestive cardiac failure. Blood cultures were negative. Thereafter it proved impossible to 0 control the haemodynamic situation. Cardiac catheter- $\overparen{D}$ ization revealed a pulmonary artery pressure of $160 \stackrel{\mathscr{P}}{\rightarrow}$ $\mathrm{mm}$. Hg. Cineangiography demonstrated the pros- 0 thesis hinged and rocking on the aortic leaflet, with $\vec{D}$ gross regurgitation around the prosthesis. The chest radiograph (Fig. 5) showed pulmonary oedema.

Operation (29 March) Anaesthesia was induced in the sitting position, and through a right antero-lateral 


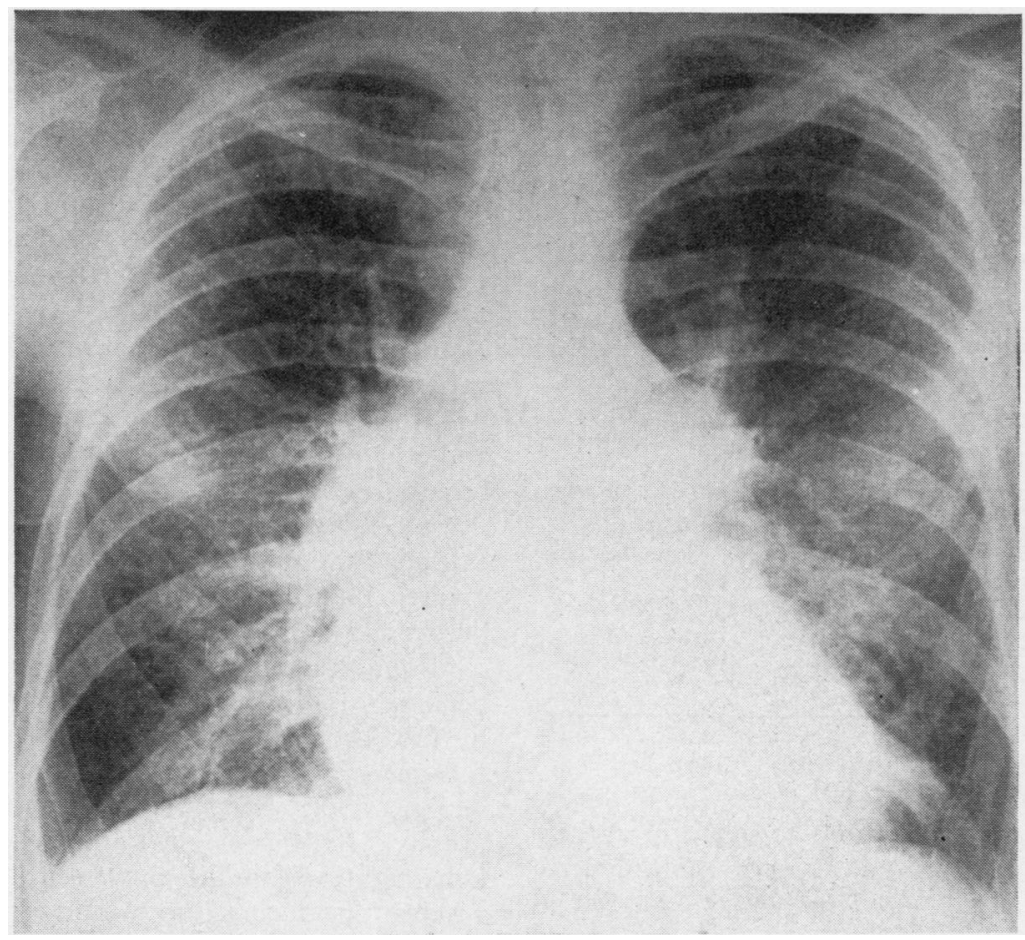

FIG. 5. Case 6.

thoracotomy a new prosthesis was inserted. The prosthetic rim had become detached from the annulus of the mural leaflet. There was friable thrombus attached to the annulus adjoining the perforation. The hinge-like action of the prosthesis had worn a deep furrow in the wall of the ventricle. The upper edge of this furrow was used for the anchoring sutures.

Post-operative Course Recovery was uneventful, the hepatomegaly and oedema disappearing within a few days. This patient has remained well since.

\section{DISCUSSION}

Hickie (1961) reported 131 deaths in a series of 279 patients with bacterial endocarditis collected from the Sydney Teaching Hospitals during the decade 1950-60. The commonest mode of death was cardiac failure. It occurred in 60 cases, and, of these, 22 had either perforation or detachment of a valve leaflet, or rupture of the chordae tendineae. In a further 54 cases vegetations were responsible for death because of systemic emboli (43), coronary emboli (10), and valve stenosis (1). The phenomena of leaflet perforation, leaflet detachment, chordal rupture, sinus of Valsalva aneursym or fistula, and the presence of vegetations are all of surgical significance (Table I).

It has become apparent that, in a certain number of cases, valve destruction is rapid and medical therapy cannot control the resultant cardiac failure (Table II). This was the situation in all cases described. Cases 1, 3, 4, 5, and 6 were terminal when surgery was undertaken and all, despite infection, should have been operated upon at an earlier date.

T A B L E I

\begin{tabular}{|c|c|c|}
\hline Case & Organism & Lesion \\
\hline 1 & $\begin{array}{l}\text { Alpha haemolytic } \\
\text { streptococcus }\end{array}$ & $\begin{array}{l}\text { Detachment of right aortic leaflet; } \\
\text { contact perforations of aortic } \\
\text { leaflet of mitral valve }\end{array}$ \\
\hline 2 & Neisseria perflava & $\begin{array}{l}\text { Perforations of right and non- } \\
\text { coronary aortic leaflets }\end{array}$ \\
\hline 3 & Streptococcus pneumoniae & $\begin{array}{l}\text { Detachment of non-coronary } \\
\text { aortic leaflet; sinus of Valsalva } \\
\text { fistula }\end{array}$ \\
\hline 4 & Unknown & $\begin{array}{l}\text { Detachment and rupture of right } \\
\text { and left aortic leaflets at } \\
\text { commissure; aneurysm of left } \\
\text { sinus of Valsalva }\end{array}$ \\
\hline 5 & Staphylococcus albus & $\begin{array}{l}\text { Chordal rupture of aortic leaflet } \\
\text { of mitral valve }\end{array}$ \\
\hline 6 & Staphylococcus albus & $\begin{array}{l}\text { Detachment of prosthesis from } \\
\text { mural aspect of mitral annulus }\end{array}$ \\
\hline
\end{tabular}


T A B LE II

\begin{tabular}{|c|c|c|c|}
\hline Case & $\begin{array}{l}\text { Clinical State } \\
\text { before Surgery }\end{array}$ & Operation & Result \\
\hline 1 & $\begin{array}{l}\text { Stuporose; marked } \\
\text { Cheyne-Stokes } \\
\text { respiration }\end{array}$ & $\begin{array}{l}\text { Aortic valve replace- } \\
\text { ment; closure of } \\
\text { perforation in }\end{array}$ & Alive and well \\
\hline 2 & $\begin{array}{l}\text { Gross clinical and } \\
\text { radiographic pul- } \\
\text { monary oedema }\end{array}$ & $\begin{array}{c}\text { Aortic valve } \\
\text { replacement }\end{array}$ & Alive and well \\
\hline 3 & $\begin{array}{l}\text { Comatose; anuric; } \\
\text { endotracheal tube } \\
\text { and assisted re- } \\
\text { spiration }\end{array}$ & $\begin{array}{l}\text { Aortic valve replace- } \\
\text { ment; closure of } \\
\text { sinus of Valsalva } \\
\text { fistula }\end{array}$ & $\begin{array}{l}\text { Died two weeks } \\
\text { after surgery; } \\
\text { Candida } \\
\text { albicans }\end{array}$ \\
\hline 4 & $\begin{array}{l}\text { Gross clinical and } \\
\text { radiographic } \\
\text { pulmonary } \\
\text { oedema }\end{array}$ & $\begin{array}{l}\text { Unable to initiate } \\
\text { bypass }\end{array}$ & Died \\
\hline 5 & $\begin{array}{l}\text { Stuporose; gross } \\
\text { pulmonary } \\
\text { oedema; blood } \\
\text { pressure } 60 \mathrm{~mm} \text {. } \\
\text { Hg; endotracheal } \\
\text { tube and assisted } \\
\text { respiration }\end{array}$ & $\begin{array}{l}\text { Mitral valve } \\
\text { replacement }\end{array}$ & $\begin{array}{l}\text { Died } 10 \text { days } \\
\text { after surgery; } \\
\text { cerebral } \\
\text { complications }\end{array}$ \\
\hline 6 & $\begin{array}{l}\text { Anasarca; pulmon- } \\
\text { ary artery pres- } \\
\text { sure } 160 \mathrm{~mm} \text {. Hg }\end{array}$ & $\begin{array}{l}\text { Mitral prosthesis } \\
\text { replacement }\end{array}$ & Alive and well \\
\hline
\end{tabular}

In cases 1,4 , and 5 delays of up to 12 hours occurred between the decision to perform corrective surgery and the actual start of the operative procedure. In cases 4 and 5 this delay contributed significantly to the fatal outcome. Case 1 survived, but ventricular fibrillation occurred on induction of anaesthesia, and the patient's condition was obviously the worse for the delay. Our present attitude, on the basis of this experience, is to perform surgery at the earliest possible hour.

Bahnson, Spencer, and Bennett (1957) drew attention to the importance of a nidus of infection within the heart when they showed that infection could be controlled by removal of an infected silk suture. Wallace, Young, and Osterhout (1965) described the first successful excision and replacement of an aortic valve perforated by active endocarditis. Case 6, though not strictly comparable with the others, illustrates the value of the removal of a large source of infection. The patient has remained well in the 18 months since the removal of the infected prosthesis. The importance of the removal of a nidus is supported by the outcome in cases 1,2 , and 5 .

The vegetations found in all cases were numerous, friable, and easily detached. Despite this, cases 1, 2, and 6 have remained free of infection since operation. Case 5 had active infection at the time of surgery, but the postoperative course and the subsequent necropsy findings suggest that the infection had been eradicated. Lerner and Weinstein (1966) have drawn attention to the incidence of clinically evident embolization occurring weeks or months after active infection has disappeared. In any of the cases described a fatal embolus might easily have occurred. The presence of such vegetations, irrespective of the degree of valve destruction, might well constitute an indication for surgery.

Yeh, Hall, and Ellison (1964) described aortic valve replacement for bacterial endocarditis occurring in pre-existing valve lesions. In cases 1 , 2 , and 3 infection occurred on previously normal valves. In cases 4 and 5 some calcification indica- $x$ tive of previous rheumatic activity was present $N$ and was apparently the focus on which infection became established.

The technical aspects of valve replacement $O$ caused the least difficulty in management. Of $\underset{-}{-}$ greater significance were the problems arising $c$ before the establishment of anaesthesia and cardiopulmonary bypass. Such patients can become rapidly and profoundly hypoxic because of low cardiac output coupled with respiratory $\vec{Q}$ failure, secondary to pulmonary oedema. A . vicious cycle is established and becomes progressive. If delay is inevitable before surgery then consideration should be given to the use of assisted respiration during the waiting period. Hypoxia ڤ was present in all six cases, but was most severe in $\stackrel{\varnothing}{\varnothing}$ cases $1,3,4$, and 5 . In cases 3 and 5 an endo- $\overrightarrow{\vec{O}}$ tracheal tube was inserted and pure oxygen was $\frac{3}{3}$ administered by intermittent positive pressure $\bar{T}$ before induction of anaesthesia. In each case induction was achieved without incident. Cases $1 \stackrel{-}{-}$ and 4 were severely hypoxic on arrival in the operating room, in spite of high-flow intranasal $\underset{\times}{\times}$ oxygen, and in each case ventricular fibrillation $\dot{0}$ occurred. The violent struggling which recurred 3 in case 4 might have been avoided if an endo- o tracheal tube had been inserted before premedication, at which time the patient was co-operative. 을 Once hypoxic restlessness is present the introduc- $D$ tion of an endotracheal tube, without anaesthesia, is likely to be lethal. A tracheostomy might be $\bar{N}$ more readily achieved, and perhaps has some 0 advantages, but there is a natural disinclination to $N$ follow tracheostomy by median sternotomy.

Premedication should be used, if at all, with great care. In case 4, rapid deterioration followed 0 its use. A pre-operative infusion of isoprenaline $\stackrel{\mathbb{D}}{\mathbb{D}}$ was found to be of some help in maintaining the $\stackrel{\infty}{+}$ circulation. Severe metabolic acidosis was often 7 present. In cases 1 and 5 the pre-operative $p H$ was 7 . This cannot be corrected unless the haemodynamic state is restored to normal.

The period of greatest danger is from the moment of induction of anaesthesia until 
intubation. Provision for monitoring the electrocardiograph and systemic arterial pressure should be made before induction. The danger of reliance on peripheral arterial pulsation and blood pressure, in patients with severe aortic incompetence, is well illustrated in cases 1 and 4 . In both the central aortic pressure was critically low in spite of apparently adequate peripheral pulsation (Table III). The pump oxygenator should be fully assembled and primed before the induction of

\begin{tabular}{|c|c|c|c|c|}
\hline Case & Brachial & $\begin{array}{l}\text { Ascending } \\
\text { Aorta }\end{array}$ & $\begin{array}{c}\text { Left } \\
\text { Ventricle }\end{array}$ & $\begin{array}{c}\text { Pulmonary } \\
\text { Artery }\end{array}$ \\
\hline $\begin{array}{l}1 \\
2 \\
3 \\
4 \\
5\end{array}$ & $\begin{array}{c}160 \cdot 20 \\
12040 \\
80^{\prime} 20 \\
130.0 \\
110^{\prime} 70 \\
\text { falling to } \\
60,40\end{array}$ & $\begin{array}{r}74 / 40 \\
100 / 40 \\
90 / 34 \\
90 / 45\end{array}$ & $\begin{array}{c}74 / 20 \\
125 / 6 \\
-1 / 36 \\
90 / 11 \\
\\
-\end{array}$ & $\begin{array}{l}\bar{z} \\
\bar{z}\end{array}$ \\
\hline & & & & \\
\hline
\end{tabular}

anaesthesia. This allows immediate establishment of bypass should circulatory arrest occur, as happened in case 4 .

Femoro-femoral bypass was not used, although it was considered, and preparations were made for its use in cases 4 and 5. On both occasions it proved just as quick to initiate cardiopulmonary bypass. Emphasis is placed on earlier intervention so that the need for supportive bypass will not arise.

All patients except cases 3 and 4 received 20 mega units sodium penicillin and $12 \mathrm{~g}$. methicillin daily for two weeks after operation. This was administered through a percutaneous polythene catheter in the right subclavian vein.

Three patients, cases 1,2 , and 6 , survived and are now well. The results achieved in these cases support the belief that, when there is an indication for surgical intervention on the basis of severe haemodynamic derangement, the infective nature of the condition should be disregarded. Case 3 died as a result of systemic infection with Candida albicans, and case 4 died as a result of cerebral damage. In both, the haemodynamic state had been restored to normal, and the return of cerebral and renal function which followed in case 3 was striking.

\section{CONCLUSION}

Six patients have been described in whom the problem involved cardiac valve replacement in the terminal stage of cardiac failure due to bacterial endocarditis.

In five of these sterilization in terms of preoperative blood cultures was achieved. This did not improve the haemodynamic state. In all, numerous friable vegetations were found at operation.

The major difficulty in management was the maintenance of an adequate circulation during the period immediately preceding induction of anaesthesia until the institution of cardiopulmonary bypass.

If, in the presence of bacterial endocarditis, the haemodynamic situation is uncontrollable, surgery should be undertaken despite infection. It should be undertaken before the patient is terminal, and cardiopulmonary bypass has then to be added to prolonged hypotension, pulmonary oedema, acidosis, and cerebral damage.

\section{REFERENCES}

Bahnson, H. T., Spencer, F. C., and Bennett, I. L. (1957). Staphylococcal infections of the heart and great vessels due to silk sutures. Ann. Surg., 146, 399.

Breslin, A., Biggs, J., and Hall, G. V. (1967). Bacterial endocarditis due to Neisseria perfava in a penicillin hypersensitive patient. In preparation.

Hickie, J. B. (1961). Bacterial endocarditis in Sydney 1950-1959. Med. J. Aust., 1, 929.

Lerner, P. I., and Weinstein, L. (1966). Infective endocarditis in the antibiotic era. New Engl. J. Med., 274, 388.

Wallace, A. G., Young, W. G., and Osterhout, S. (1965). Treatment of acute bacterial endocarditis by valve excision and replacement. Circulation, 31, 450.

Yeh, T. J., Hall, D. P., and Ellison, R. G. (1964). Surgical treatment of aortic valve perforation due to bacterial endocarditis. A report of six cases. Amer. Surgn, 30, 766.

\section{ADDENDUM}

Two further patients in uncontrollable cardiac failure have had aortic valve replacement since this paper was submitted. In one, blood cultures were positive at the time of surgery. Both are now well. 